\title{
Combined intracerebral and cranial epidural hydatid cysts: case report
}

\begin{abstract}
Background: Hydatid cyst ( $\mathrm{HC}$ ) is a parasitic disease caused by Echinococcus granulosus. Involvement of the central nervous system (CNS) is very rare in this parasitic infection and the association of intracerebral and epidural $\mathrm{HC}$ is exceptional.

Patient and method: A 6year-old female who was operated three years ago for a left frontal intracerebral hydatid cyst in Toto without rupture and without medical treatment following the surgery, and who came with the history of headache and vomiting for 4 months is reported. Computed tomography of the brain showed a large $5 \times 6 \times 5 \mathrm{~cm}$, cystic lesion with a density similar to the cerebrospinal fluid in the left frontal region with another adjacent small cyst in epidural space. The patient underwent left frontal craniotomy. The patient was treated by Dowling technique for intracerebral cyst and by cyst aspiration after rupture.
\end{abstract}

Conclusion: Hydatid cysts in epidural location are very rare and can be primary or after recurrence. The mainstay of treatment is surgical removal of the cyst. Medical therapy is also important to prevent recurrences during the postoperative period.

Keywords: hydatid cyst, epidural, echinococcus, cranial cyst, intracerebral, postoperative, medical therapy, treatment, surgical, recurrence
Volume 2 Issue 2 - 2017

\author{
Said Hilmani,Adil Maati,Abdessamad El \\ Azhari \\ Neurosurgical Department, Hassan II University, Morocco
}

Correspondence: Said Hilmani, Neurosurgical Department, Hassan II University, UHC Ibn Rochd, Morocco, Tel

212664440642,Email hilmanisaid@yahoo.com

Received: October 09, 2016 | Published: February 27, 2017

\section{Introduction}

Hydatid disease is a parasitic infestation caused by Echinococcus granulosus in Mediterranean countries and is endemic in some regions of the world. ${ }^{1}$ Hydatid disease has been reported with varying frequency in most body organs. The involvement of central nervous system was reported about $2-4 \%{ }^{2}$ Cerebral cysts are more common in the paediatric population with a male predominance. ${ }^{3}$ They are commonly located supratentorially in the watershed regions of the middle cerebral artery. ${ }^{4}$ Primary or secondary Epidural occurrence of hydatid cysts is very rare and exceptional where it associated with separate intracerebral localisation. Almost always a single lesion is seen, multiple or recurrent hydatid cysts in the brain are rarely reported. ${ }^{5}$ Here we report an exceptional case of a child diagnosed by two separate intracranial cerebral and epidural hydatid cysts.

\section{Case report}

An eight-year-old girl underwent surgery for the removal of an intracerebral frontal left hydatid cyst three years ago. She didn't take any regular medical therapy following surgery. She came with intermittent headaches and vomiting for two months. There was no history of recent trauma. Physical examination revealed a healthy child in no distress. There was no frontal syndrome. Chest $\mathrm{X}$ rays and abdomen ultrasonography were normal. CT scan revealed a relatively large left frontal cystic lesion of similar density to cerebrospinal fluid, with another small separate one in the epidural space in the adjacent region close to the midline, associated to bone exostosis around the cyst without bone defect (Figure 1). No rim enhancement was seen. Laboratory tests were normal. The patient underwent a left frontal craniotomy which revealed intracerebral and epidural hydatid cysts (Figure 2). The intracerebral cyst was completely removed following the Dowling's technique, whereas the epidural one ruptured because It was seen that the inner part of the cranium overlying the cyst was thickened and the membrane of the cyst was adherent to the cranium. The contents of the cyst aspirated without any contagion and the cavities were irrigated with warm hypertonic saline solution. The epidural cyst membrane removed totally and dura underlying was normal. The dinner table was eroded by the mass without total defect. There was no evidence to suggest that both cysts communicate between each other. The postoperative course of the patient was uneventful. CT scan control showed a complete removal of the two cysts without recurrence (Figure 3). Following the surgery, the patient received oral Albendazole $(15 \mathrm{mg} / \mathrm{kg} / \mathrm{day})$. She is doing well at 6 months follow-up.
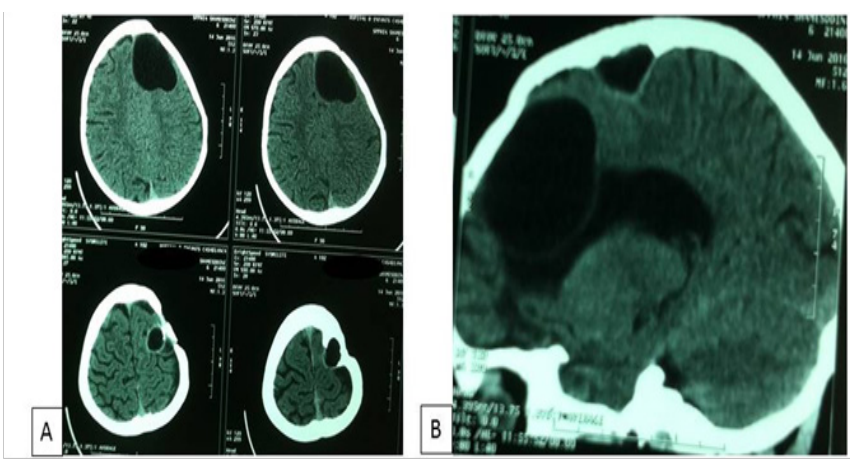

Figure I Axial CT scan contrast (A) showing a homogeneous, cystic, no enhanced left intracerebral frontal lesion with an adjacent small one in convex inner margin indicating extradural location, associated to exostosis. The sagittal view (B) shows the extent of the frontal hydatid cyst towards the frontal horn of the left lateral ventricle and a separate epidural cyst. 


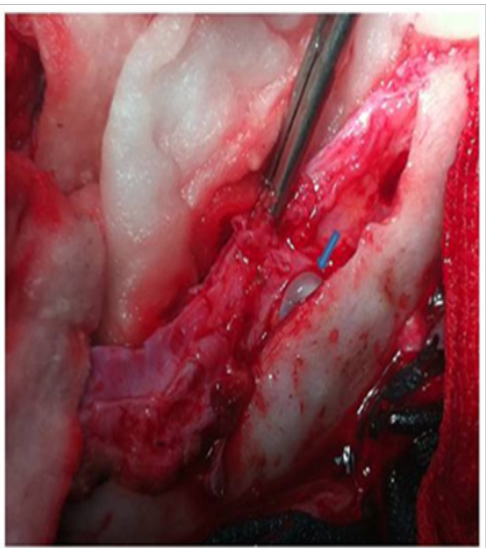

Figure 2 Intra-operative photograph of the intact epidural hydatid cyst below the frontal bone (blue arrow).

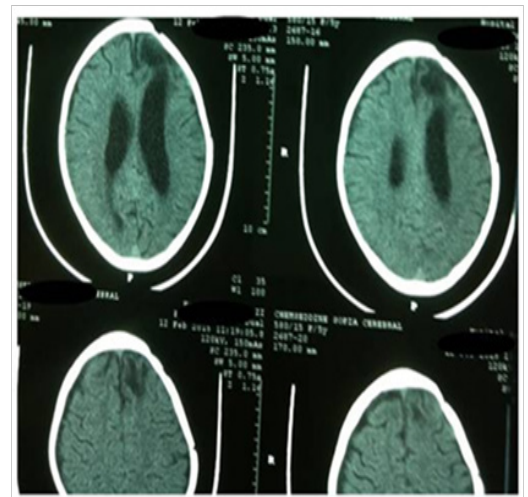

Figure 3 Post-operative CT scan showing the complete removal of the cysts without recurrence.

\section{Discussion}

Echinococcosis Granulosus, the agent responsible for hydatid disease, causes the cyst formation in human. ${ }^{6}$ Brain $(1-3 \%)$ is one of the rare involved organs by the haematogenous dissemination. ${ }^{7,8}$ However, only $2 \%$ of hydatid cysts are localized in the skeleton and of these 3 to $4 \%$ are found in the skull. ${ }^{1}$ Three forms of central nerve system hydatid disease occurring in intracranial were described: intracerebral, cranial extradural, and a combined form. In this third form, extradural $\mathrm{HC}$ may develop through dura defect as reported in our previous published case $^{9}$ or with a normal dura. The mechanism may be an embolization of scolices or embryos via blood vessels in primary form with tendency to occur around the midline; may be due to the existence of a rich venous vascularization in this area, ${ }^{10}$ or secondary to previous cyst rupture. This is most likely in our case. The lesions may cause no symptoms until they become quite large. ${ }^{11,12}$ Most common symptoms are headache, vomiting, nausea, and focal neurological signs like weakness of extremities. ${ }^{12-14}$ Most of the symptoms tend to disappear after successful removal.

Both cranial CT scan and MRI demonstrate the hydatid cysts adequately, revealing solitary, homogeneous, spherical and large parenchymal cysts with well-defined borders, without perifocal oedema or contrast enhancement. ${ }^{12,15}$ In bone window, CT can show some bone reactions around epidural cyst, like defect ${ }^{2}$ or exostosis as seen in this case.

To remove unruptured cerebral hydatid cysts, the Dowling technique $^{16}$ is recommended and safe surgical procedure to avoid ruptures that could result in serious complications such as anaphylactic shock, meningitis or recurrences. ${ }^{14}$ This technique is also recommended for epidural cyst, ${ }^{4}$ but could not be performed effectively in our patient as reported by Behari $\mathrm{S}$ et al., ${ }^{10}$ because the epidural hydatid cysts adhered to dura mater and osseous trabeculae. So bone location is easily ruptured during the surgical procedure.

Medical treatment with Albendazole both pre- and postoperatively was suggested in cases of recurrences, intra-operative cyst rupture, as well as when giant or multiple hydatid cysts are encountered. ${ }^{12}$ Long-term follow-up in patients with cerebral hydatid cyst disease having surgery without intra-operative cyst rupture has confirmed a very good outcome. ${ }^{17}$

\section{Conclusion}

Hydatid cysts in epidural location are very rare and can be primary or after recurrence. The mainstay of treatment is surgical removal of the cyst. Medical therapy is also important to prevent recurrences during the postoperative period. Epidural $\mathrm{HC}$ is extremely rare but it should be considered as differential diagnosis of cranial epidural cystic lesion in endemic countries.

\section{Acknowledgements}

None.

\section{Conflict of interest}

Author declares that there is no conflict of interest.

\section{References}

1. Erman T, Tuna M, Göçer I, et al. Intracranial intraosseous hydatid cyst. Case report and review of literature. Neurosurg Focus. 2001;11(1):ECP1.

2. Okten AI, Ergun R, Gezercan Y. Primary intracranial extradural hydatid cyst localized in the supra- and infra-tentorium. Acta Parasitol. 2006;61(4):309-310.

3. Onal C, Unal F, Barlas O, et al. Long-term follow-up and results of 30 pediatric intracranial hydatid cysts: half a century of experience in the department of neurosurgery of the school of Medicine at the university of Istanbul (1952-2001). Pediatr Neurosurg. 2001;35(2):72-81.

4. Cemil B, Tun K, Gurcay AG, et al. Cranial epidural hydatid cysts: Clinical report and review of the literature. Acta Neurochir. 2009;151(6):659-662.

5. Yurt A, Avci M, Selcuki M, et al. Multiple cerebral hydatid cysts. Report of a case with 24 pieces. Clin Neurol Neurosurg. 2007;109(9):821-826.

6. Beskonaklı E, Cayli S, Yalcınlar Y. Primary intracranial extradural hydatid cyst extending above and below the tentorium. Br J Neurosurg. 1996;10(3):315-316.

7. Kiresi DA, Karabacakoglu A, Odev K, et al. Uncommon locations of hydatid cysts. Acta Radiol. 2003;44(6):622-636.

8. McManus DP, Zhang W, Li J, et al. Echinococcosis. Lancet. 2003;362(9392):1295-1304.

9. Hilmani S, Bertal A, Lakhdar A, et al. Craniocerebral hydatid cyst. Case illustration. J Neurosurg. 2006;105(1 Suppl):77.

10. Behari S, Banerji D, Phadke RV, et al. Multiple infected extradural parasellar hydatid cysts. Surg Neurol. 1997;48(1):53-57.

11. Khaldi M, Mohamed S, Kallel J, et al. Brain hydatidosis: report on 117 cases. Child Nerv Syst. 2000;16(10):765-769.

12. Limaiema F, Bellil S, Bellil K, et al. Primary hydatidosis of the central nervous system: A retrospective study of 39 Tunisian cases. Clin Neurol Neurosurg. 2010;112(1):23-28. 
13. Duishanbai S, Jiafu D, Guo H, et al. Intracranial hydatid cyst in children: report of 30 cases. Childs Nerv Syst. 2010;26(6):821-827.

14. Guvenc G, Ozdemir N, Yildirim L. Successful treatment of hydatid cyst into the lateral ventricle with Dowling's technique in an adult patient. $J$ Neurol Sci. 2011;28:265-269.

15. Bukte Y, Kemaloglu S, Nazaroglu H, et al. Cerebral hydatid disease: CT and MR imaging findings. Swiss Med Wkly. 2004;134(31-32):459-467.
16. Izci Y, Tuzun Y, Secer HI, et al. Cerebral hydatid cysts: Technique and pitfalls of surgical management. Neurosurg Focus. 2008;24(6):E15.

17. Ciurea AV, Fountas KN, Coman TC, et al. Long-term surgical outcome in patients with intracranial hydatid cyst. Acta Neurochir (Wien). 2006;148(4):421-426. 